\title{
Concentrations of selected proteins and homocysteine in patients with atherosclerosis
}

\author{
Eugeniusz Hrycek¹, Piotr Buszman'1, Aleksander Żurakowski', Iwona Banasiewicz- Szkróbka1, \\ Przemysław Nowakowski', Justyna Dworak², Paweł Buszman ${ }^{1,2}$ \\ 1 American Heart of Poland, Ustroń, Poland \\ 2 Department of Internal, Autoimmune and Metabolic Diseases, Medical University of Silesia, Katowice, Poland
}

Correspondence to:

Eugeniusz Hrycek, MD, American Heart of Poland, ul. Sanatoryjna 1, 43-450 Ustroń, Poland, phone: +48322544807 , email: ehrycek@gmail.com Received: May 8, 2019. Revision accepted: July 29, 2019. Published online: August 5, 2019. Kardiol Pol. 2019; 77 (10): 966-968 doi:10.33963/KP.14921

Copyright by the Author(s), 2019
Introduction The development of atherosclerosis is associated not only with endothelial dysfunction (due to inflammation or injury) and subendothelial lesions but also with coagulation disorders and systemic metabolic abnormalities. However, studies in this area often provide inconsistent results. Therefore, we decided to investigate selected autoimmune markers, proteins involved in coagulation, and homocysteine in patients with atherosclerosis, with the aim to identify biomarkers of the risk and progression of atherosclerosis.

Methods A total of 78 men and women (age range, 54-77 years) diagnosed with atherosclerosis on the basis of clinical signs and symptoms as well as angiography results were divided into 3 groups: 33 patients with coronary artery disease (CAD), 15 patients with peripheral artery disease (PAD), and 30 patients with both coronary and peripheral artery disease (CPAD). A wide range of peripheral blood tests were performed using an enzyme-linked immunosorbent assay reader ( $\mu$-Quant, BioTek Instruments, Inc., Winooski, Vermont, United States). The following parameters were determined: 1) blood coagulation-protein $C$, free protein $S$, and annexin V; 2) autoimmune markers - antineutrophil cytoplasmic antibodies (pANCAs and cANCAs), antinuclear antibodies (ANAs), anti-double-stranded DNA (anti-dsDNA) antibodies, antiendothelial cell antibody (AECA) index, anticardiolipin antibodies (ACAs) (immunoglobulins $\mathrm{G}$ [IgG] and $\mathrm{M}$ [IgM]); and 3) homocysteine levels to identify metabolic disorders. Blood samples were collected between 7:00 and 8:00 AM, and serum or plasma samples were immediately coded and stored at $-80^{\circ} \mathrm{C}$ until the assay.
The exclusion criteria were as follows: concomitant chronic liver or kidney diseases, collagenoses, thyroid disease, immunosuppressive therapy (during the past 12 months), history of malignancy, and acute or chronic inflammatory disease (excluded on the basis of medical history, medical examination, and determination of serum $C$-reactive protein levels, which were within the reference range in our patients, ie, $<5 \mathrm{mg} / \mathrm{l}$ ). Patients with psoriasis were also excluded.'

The study protocol included: 1) a comparative analysis of laboratory results in the CAD, PAD, and CPAD groups; and 2) evaluation of correlations between the investigated parameters in the CAD, PAD, and CPAD groups.

The study was approved by the local bioethics committee. All patients provided their written informed consent to blood sampling.

Statistical analysis The Shapiro-Wilk test was used to assess the normality of distribution, followed by the calculation of the arithmetic mean and standard deviation. The following tests were performed: Mann-Whitney test, Spearman correlation coefficient, Kruskal-Wallis test, $t$ test, and 1-way analysis of variance (ANOVA). Differences with a $P$ value of 0.05 or lower were considered significant. We revealed differences between the mean and median values for a few parameters; however, as they were comparable for most studied parameters, mean (SD) values were calculated in the comparative analysis.

Results and discussion The Kruskal-Wallis test revealed that the differences in the mean levels of annexin $V$ between the $C A D, P A D$, and CPAD groups approached statistical significance $(P=$ 
0.057). The 1-way ANOVA showed differences in protein $C$ levels between the $C A D, P A D$, and $C P A D$ groups $(P=0.02)$ (Supplementary material, Table $S 1)$.

The comparative analysis of laboratory investigations between the CAD, PAD and CPAD groups is presented in TABLE1. In the PAD group, the mean protein $C$ level and the AECA index exceeded the upper reference limit $(6.5 \mu \mathrm{g} / \mathrm{ml}$ and 0.165 , respectively). In the whole study group, 10 participants (13\%) had ANA levels exceeding the upper reference limit ( $25 \mathrm{AU} / \mathrm{ml})$. The same was observed for homocysteine levels $(>15 \mu \mathrm{mol} / \mathrm{l})$ in 17 participants $(22 \%)$.

In the CPAD group, more often than in the $C A D$ and PAD groups, significant or nearly significant inverse correlations were observed between the following parameters: protein $C$ and cANCAs $(r=-0.51 ; P=0.004)$, protein $S$ and the AECA index $(r=-0.36 ; P=0.052)$, annexin $\mathrm{V}$ and homocysteine $(r=-0.47 ; P=0.01)$, anti-dsDNA antibodies and homocysteine $(r=-0.38$; $P=0.04)$, as well as the AECA index and homocysteine $(r=-0.51 ; P=0.004)$. Positive correlations were shown between protein $S$ and homocysteine $(r=0.35 ; P=0.058)$, annexin $\mathrm{V}$ and the AECA index $(r=0.56 ; P=0.002)$, pANCAs and cANCAs ( $r=0.50 ; P=0.006)$, pANCAs and ANAs $(r=0.42 ; P=0.02)$, pANCAs and IgG ACAs $(r=0.48 ; P=0.008)$, cANCAs and ANAs $(r=0.37$; $P=0.048)$, cANCAs and IgG ACAs $(r=0.39$; $P=0.03)$, ANAs and anti-dsDNA antibodies $(r=0.55 ; P=0.002)$, as well as anti-dsDNA antibodies and the AECA index $(r=0.31 ; P=0.093)$.

In the CAD group, significant or nearly significant positive correlations were noted between
cANCAs and anti-dsDNA antibodies ( $r=0.39$; $P=0.03)$, ANA and anti-dsDNA antibodies $(r=0.39 ; P=0.03)$, ANAs and IgG ACAs $(r=0.34$; $P=0.053)$, anti-dsDNA antibodies and the AECA index $(r=0.33 ; P=0.061)$, homocysteine and IgM ACAs $(r=0.39 ; P=0.02)$, as well as homocysteine and IgG ACAs ( $r=0.35 ; P=0.04)$, while negative correlations were revealed between the AECA index and homocysteine $(r=-0.60 ; P<0.001)$.

In the PAD group, positive correlations were observed between pANCAs and ANAs $(r=0.54$; $P=0.04)$, ANAs and anti-dsDNA antibodies $(r=0.76 ; P=0.002)$, ANAs and IgG ACAs $(r=0.53$; $P=0.047)$, as well as anti-dsDNA antibodies and IgG ACAs $(r=0.60 ; P=0.02)$.

Patients with CAPD had the lowest protein $C$ levels in peripheral blood, which might have contributed to the development and extent of angiopathy; however, the mean protein $C$ concentrations in these patients were within the reference range. The PAD group, on the other hand, had the lowest free protein $S$ levels (although still within the reference range) and the lowest annexin $\mathrm{V}$ levels.

In the CPAD group, we showed correlations of the coagulation components (protein $C$, protein $S$, and annexin $V$ ) with autoimmune parameters (cANCAs, AECA index) and homocysteine. However, these results are difficult to interpret because data on this topic are scarce. Some reports have indicated an association between hypercoagulability and the development or progression of atherosclerosis. ${ }^{2,3}$ Interestingly, Vig et $\mathrm{al}^{4}$ identified thrombophilia in one-fourth of their study population with PAD. Moreover, plasma

TABLE 1 Comparative analysis of protein and homocysteine concentrations in patients with atherosclerosis

\begin{tabular}{llll} 
Parameter & CAD $(n=33)$ & CPAD $(n=30)$ & PAD $(n=15)$ \\
\hline Protein $C, \mu \mathrm{g} / \mathrm{ml}$ & $6.09(1.97)^{\mathrm{c}}$ & $5.00(1.82)^{\mathrm{a}, \mathrm{b}}$ & $6.75(2.66)^{\mathrm{c}}$ \\
\hline Free protein $\mathrm{S}, \%$ & $129.11(13.09)^{\mathrm{b}}$ & $125.97(13.06)$ & $121.42(12.76)^{\mathrm{a}}$ \\
\hline Annexin $\mathrm{V}, \mu \mathrm{g} / \mathrm{ml}$ & $3.74(2.03)$ & $4.23(1.98)^{\mathrm{b}}$ & $3.37(1.94)^{\mathrm{c}}$ \\
\hline pANCAs, AU/ml & $2.81(1.93)$ & $6.87(9.73)$ & $3.54(4.75)$ \\
\hline cANCAs, AU/ml & $2.61(2.31)$ & $5.22(7.56)$ & $4.25(2.77)$ \\
\hline ANAs, AU/ml & $17.59(35.95)$ & $16.44(15.62)^{\mathrm{b}}$ & $8.33(8.04)^{\mathrm{c}}$ \\
\hline IgG anti-dsDNA antibodies, IU/ml & $3.67(1.35)$ & $3.94(1.47)$ & $3.50(1.67)$ \\
\hline AECA index & $0.04(0.03)$ & $0.11(0.32)$ & $0.17(0.27)$ \\
\hline Homocysteine, $\mu$ mol/l & $13.53(5.95)$ & $12.86(4.35)$ & $12.49(4.62)$ \\
\hline IgM ACAs, AU/ml & $3.49(0.85)$ & $4.10(4.40)$ & $7.58(16.53)$ \\
\hline IgG ACAs, AU/ml & $3.63(0.66)$ & $3.80(1.08)$ & $3.76(0.76)$ \\
\hline
\end{tabular}

Data are presented as mean (SD).

a $P \leq 0.05$ vs CAD; b $P \leq 0.05$ vs PAD; $\quad$ c $P \leq 0.05$ vs CPAD

Abbreviations: ACA, anticardiolipin antibodies; AECA, antiendothelial cell antibodies; ANA, antinuclear antibodies; ANCA, antineutrophil cytoplasmic antibodies; anti-dsDNA, anti-double-stranded DNA; CAD, coronary artery disease; CPAD, coronary and peripheral artery disease; CRP, C-reactive protein; IgG, immunoglobulin G; IgM, immunoglobulin M; PAD, peripheral artery disease 
annexin $\mathrm{V}$ levels were reported to be inversely correlated with the severity of coronary stenosis, ${ }^{5}$ and patients in the acute phase of myocardial infarction were shown to have low plasma annexin V levels. ${ }^{6}$

Patients with CPAD also showed correlations between ANCAs (both pANCAs and cANCAs) and IgG ACAs. These correlations, together with the correlations between ANAs and pANCAs in the PAD and CPAD groups, between anti-dsDNA antibodies and CANCAs in the CAD group, and between cANCAs and ANAs in the CPAD group, seem to provide evidence for a potential association between ANCAs and prothrombotic factors as well as between ANAs and anti-dsDNA antibodies.

The interest in ANCAs mainly stems from their association with vasculitis. Vascular inflammation has been implicated as a causative agent in atherosclerosis, and some authors believe the inflammatory process to be the predominant initiating factor. However, it should be noted that a negative ANCA test does not exclude vasculitis, while positive results do not unequivocally confirm the disease. ${ }^{7}$

In our study, several individuals with CAD and CPAD had ANA levels exceeding the upper reference limits. Similar findings were reported for the AECA index in the PAD and CPAD groups. In addition, we observed a positive correlation between the AECA index and anti-dsDNA antibodies in the CAD and CPAD groups. These findings might suggest some atherosclerosis-related processes with endothelial involvement and are consistent with a higher prevalence of AECAs in patients with ischemic heart disease. ${ }^{8}$

Although the upper reference limits of anti-dsDNA antibodies, IgG ACAs, pANCAs, and cANCAs were not exceeded in our study population, the observed correlations between these antibodies and ANAs are noteworthy and warrant large cohort studies, particularly that the role of ANAs in atherogenesis has not been elucidated.

Several participants in each of the groups met the criteria for hyperhomocysteinemia. The CAD group showed a significant positive correlation between IgG and IgM ACAs and homocysteine levels, while patients with CPAD revealed a negative correlation between homocysteine and anti-dsDNA antibodies. In addition, in the PAD group, a positive correlation between anti-dsDNA antibodies and IgG ACAs was observed. Interestingly, some antiphospholipid antibodies were more prevalent in patients in the acute phase of myocardial infarction, ${ }^{9}$ which seems to support the concept of immune mechanisms and coagulation abnormalities in the pathogenesis of atherosclerosis. Homocysteine and antiphospholipid antibodies exert similar biological effects in hemostasis, but the interactions between them remain unclear.

Interestingly, the CAD group showed a negative correlation between homocysteine levels and the AECA index. This relationship was also revealed in the $C P A D$ group, but not in the $\mathrm{PAD}$ group. However, it is hard to explain these findings. It is also difficult to analyze the role of this correlation in the pathogenesis of atherosclerosis, particularly because there have not been any previous reports on this topic.

In conclusion, our results suggest that autoimmunity and homocysteine might be involved in the pathogenesis of CAD, PAD, and CPAD in selected cases. Further studies on larger groups of patients are needed to elucidate the correlations between the analyzed parameters, observed most frequently in patients with CPAD, and to clarify their significance for clinical practice.

\section{SUPPLEMENTARY MATERIAL}

Supplementary material is available at www.mp.pl/kardiologiapolska.

\section{ARTICLE INFORMATION}

\section{CONFLICT OF INTEREST None declared.}

OPEN ACCESS This is an Open Access article distributed under the terms of the Creative Commons Attribution-NonCommercial-NoDerivatives 4.0 International License (CC BY-NC-ND 4.0), allowing third parties to download articles and share them with others, provided the original work is properly cited, not changed in any way, distributed under the same license, and used for noncommercial purposes only. For commercial use, please contact the journal office at kardiologiapolska@ptkardio.pl.

HOW TO CITE Hrycek E, Buszman P, Żurakowski A, et al. Concentrations of selected proteins and homocysteine in patients with atherosclerosis. Kardiol Pol. 2019; 77: 966-968. doi:10.33963/KP.14921

\section{REFERENCES}

1 Haberka M, Bańska-Kisiel K, Bergler-Czop B, et al. Mild to moderate psoriasis is associated with oxidative stress, subclinical atherosclerosis, and endothelial dysfunction. Pol Arch Int Med. 2018; 128: 434-439.

2 Komai $\mathrm{H}$, Shindo S, Sato M, Ogino H. Reduced protein C activity might be associated progression of peripheral arterial disease. Angiology. 2015; 66: 584-587.

3 Pankow JS, Tang W, Pankratz N, et al. Identification of genetic variants linking protein C and lipoprotein metabolism: the ARIC Study (Atherosclerosis Risk in Communities). Arterioscler Thromb Vasc Biol. 2017; 37: 589-597.

4 Vig S, Chitolie A, Bevan D, et al. The prevalence of thrombophilia in patients with symptomatic peripheral vascular disease. Br J Surg. 2006; 93: 577-581.

5 Ewing MM, deVries MR, Nordzell M, et al. Annexin A5 therapy attenuates vascular inflammation and remodeling and improves endothelial function in mice. Arterioscler Thromb Vasc Biol. 2011; 31: 95-101.

6 Shojale M, Sotoodah A, Roozmeh S, et al. Annexin V and anti-annexin V antibodies: two interesting aspects in acute myocardial infarction. Thromb J. 2009; 7: 13.

7 Życińska K, Borowiec A. Atherosclerosis in antineutrophil cytoplasmic autoantibody (ANCA)-associated vasculitis. Kardiol Pol. 2018; 76: 77-82.

8 Farsi A, Domeneghetti MP, Brunelli T, et al. Activation of the immune system and coronary artery disease: the role of anti-endothelial cell antibodies. Atherosclerosis. 2001; 154: 429-436.

9 Jahromi AS, Shojale M, Dana S, Madani A. Anti-cardiolipin antibody in acute myocardial infarction. Am J Immunol. 2010; 6: 11-14. 